\title{
Design of Intelligent Manufacturing Big Data Cloud Service Platform
}

\author{
Danlin Cai ${ }^{1,2,3,4}$, Mingyu Chen ${ }^{1,2,3,4}$, Daxin zhu ${ }^{1,3,4,5}$, Junjie Liu ${ }^{1,2,3}$ \\ ${ }^{1}$ Quanzhou Normal University, China \\ ${ }^{2}$ Fujian Provincial Key Laboratory of Data-Intensive Computing, China \\ ${ }^{3}$ Fujian University Laboratory of Intelligent Computing and Information Processing, China \\ ${ }^{4}$ Fujian Provincial Big Data Research Institute of Intelligent Manufacturing, China
}

\begin{abstract}
With the coming of the intelligent manufacturing, the technology and application of industrial big data will be popular in the future. The productivity, competitiveness and innovation of the manufacturing industries will be improved through the integrated innovation of big data technology and industries. Besides, products, production process, management, services, new form and new models will be more intellectualized. They will support the transformation and upgrading of manufacturing industry and the construction of an open, shared and collaborative ecological environment for intelligent manufacturing industry.
\end{abstract}

\section{Background}

In recent years, due to the popularity of Internet and smart phones, data size tends to have an explosive growth. According to the prediction of International Data Corporation IDC, world's data may double every two years and till 2020, the data volume stored in electronic forms will reach $35 \mathrm{ZB}$. Humans have entered the age of big data. With the deep integration of informatization and industrialization, the information technology has permeated into all aspects of industrial chains, bringing abundant data owned by industrial enterprises. Industrial big data are data produced in the informationization application process of industrial fields and they are featured by large scale, multi-sources, continuous sampling, low value density and strong dynamic nature. Big industrial data has become an important driving force for the new round of industrial revolution.

Industry is the foundation and pillar of the national economy as well as an important symbol of a country's economic strength and competitiveness. With the development of emerging technologies such as cloud computing, big data and Internet of Things, a new round of industrial revolution has taken shape in the world with manufacturing transformation and upgrading as the most important task. The major industrialized developed countries in the world have formulated industrial redevelopment strategies. In February 2012, the United States released the "National Strategic Plan for Advanced Manufacturing", which will promote the development of advanced manufacturing industries to the national strategic level. The National Strategic Plan for Advanced Manufacturing provides three major principles, five major goals and corresponding countermeasures to promote the development of the advanced manufacturing industry in the United States from the aspects of investment, labor force and innovation. In April 2015, Germany proposed the "Industry 4.0" strategy, emphasizing that through the full integration of information network and industrial production system, the products and production equipment, the vertical and inner parts of the factory, the factories and factories can all be integrated through the CPS (Physical Information System) to realize the production intellectualization, enhance manufacturing flexibility and engineering efficiency. In 2015, France launched the "New Industrial Policy in France" with an overall layout of "one core and nine major fulcrums."

One core refers to "future industry". The main content is to achieve the transformation from industrialization to digitization and intellectualization as well as the business model transformation driven by transformation and upgrading of production tools. Nine major fulcrums include new resource development, sustainable cities, environmentally friendly vehicles, internet technology, big data technology and new medicine etc. In May 2015, the State Council formally issued the "Made in China 2025" program. The program put forward to focus on promoting the integration of information technology and industry with the intelligent manufacturing as the main direction, developing intelligent equipment and products, promoting the production intellectualization of the process, cultivating new production methods and realizing intelligent production and intelligent manufacturing through the construction of intelligent factories.

\section{Problem of Intelligent Manufacturing Big Data Urgently Needs to Be Solved}


China's economic development has entered a period of new normal. The state vigorously implements innovationdriven strategy with manufacturing industry as the mainstay of the national economy. Industry 4.0 is the fourth industrial revolution led by intelligent manufacturing. "Made in China 2025" is a strategic program at the national level, which aims to speed up the integration of a new generation of information technology and manufacturing industries as the main line and promote intelligent manufacturing as the main direction with the goal of meeting the needs of major technological equipment for economic and social development and national defense construction so as to realize the historic transition of manufacturing industry from big to strong by strengthening industrial fundamental ability, enhancing the level of comprehensive integration, improving multi-level and multi-type personnel training system, promoting industrial transformation and upgrading and cultivating manufacturing culture with Chinese characteristics.

The key issues facing by intelligent manufacturing industry are the transformation from mechanization and automation to digitization and intelligent manufacturing, from focusing on growth rate to focusing on quality and efficiency, and from production-oriented manufacturing to service-oriented manufacturing. In this process, urgent solutions are needed for three important issues.

(1) How to promote the application of big data in all aspects of the industrial chain so as to achieve networking and intellectualization in the manufacturing industry, and to enhance the production technology and efficiency of industrial enterprises?

(2) How to promote the integration and development of a new generation of information technologies such as big data, Internet of Things, and cloud computing so as to promote the transformation and upgrading of traditional industries and the acceleration of the development of new industries?

(3) How to make use of big data to promote the deep integration of informatization and industrialization, propel the gathering of industry data and carry out the application of big data fusion in the industry?

Solving these three major issues will have a direct bearing on exploring a new mode of advanced manufacturing in China and enhancing our ability to provide typical experiences and exemplary leadership for the "Made in China 2025" to accelerate its implementation nationwide.

\section{Main Service Contents of Intelligent Manufacturing Big Data Platform}

The problem of effective management of huge data resources and the management of massive data mining has become a common issue that needs to be faced and solved by academia and industry. As shown in Figure 1, we conducted a three-level big data application for the intelligent manufacturing industry.

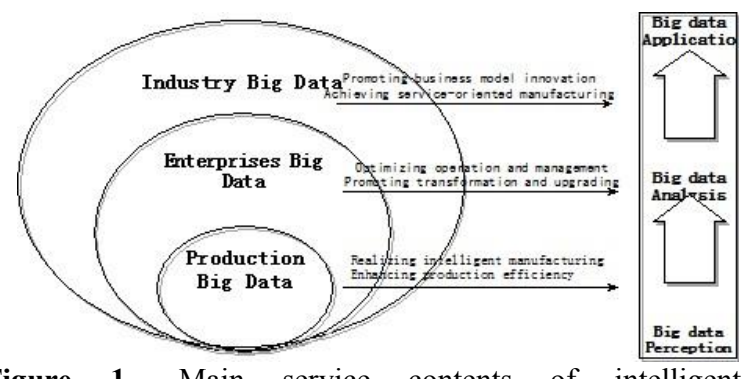

Figure 1. Main service contents of intelligent manufacturing big data platform

(1) Intelligent manufacturing and production big data can be used to achieve networking and intellectualization of manufacturing industry and establish advanced production system to realize intelligent production so as to enhance enterprise production technology and efficiency.

The workshop management level needs to be improved. Production line sensors can be used to collect temperature, pressure, heat, vibration, noise and other data so as to achieve several results, including equipment diagnosis, electricity consumption analysis, energy consumption analysis and quality accident analysis. Big data can be used in the production process to analyze and optimize the entire work flow. It integrates and aggregates the data of all aspects of production and manufacturing, establishes a virtual model for the production process of industrial products, simulates and optimizes the production work flow, and makes an integrated analysis of the manufacturing data of various links, which is conductive to improve and optimize the production process and promote the establishment of a modern production system. Through automated and intelligent control of the entire manufacturing process, information sharing, system integration and business collaboration are promoted. Scientific decision-making in the production work flow, and the automation, personalization, flexibility and self-optimization of the production process at the greatest extent will lead to the realization of intelligent manufacturing with precise, high-end and agile manufacturing capabilities.

(2) Intelligent manufacturing enterprise big data can be used to achieve lean management and promote transformation and upgrading of enterprise by optimizing the operation and management system as well as the industrial supply chain. RFID and other electronic identification technology, Internet of Things technology and mobile Internet technology can help industrial enterprises to obtain a complete big data of product supply chain. By analyzing these data, the efficiency of storage, distribution and marketing will be significantly improved and the cost will be sharply declined, which will optimize the supply chain and promote the convergence and optimization of the whole process of operation and management of intelligent manufacturing enterprises. The integration of resources such as production data, financial data, management data, purchasing data, sales data and consumer behavior data will help enterprises to find the best investment proportion of production factors through data mining analysis, and to realize research and development, supply 
and marketing, operation and management, production control, seamless integration of business and financial processes as well as business collaboration so as to promote the integration, reorganization and optimization of business, decision-making and operational processes.

(3) Intelligent manufacturing industry big data can be used to promote in-depth integration of information technology and industrialization, propel enterprises to gather industry data and accelerate business model innovation so as to realize service-oriented manufacturing. The use of big data can also help intelligent manufacturing enterprises to innovate their products and services by developing new business model. The realtime monitoring of product operating status can be conducted through embedded sensors in products and the product sales data and customer data can be obtained through the business platform. By analyzing and predicting these data, intelligent manufacturing enterprises can develop various online value-added services, including fault early warning, remote monitoring, remote operation and maintenance and quality diagnostics etc. The personalized, online and convenient value-added services will expand the product value space and realize the transformation of operation model from product-oriented model to "manufacturing + service" model as well as provide relevant services and decision-making basis for other industries.

\section{Design of Intelligent Manufacturing Big Data Platform}

For big data application in intelligent manufacturing from workshop to enterprise to industry, from point to surface, it still follows the general rules of the big data system, that is, big data perception (acquisition), big data analysis and big data application. The goal of intelligent manufacturing big data application is to build a data chain which covers the whole procedure, process of industry and the whole life cycle of the product. Figure 2 shows the main link of intelligent manufacturing big data in practical application, which includes data perception, data analysis, data application and other three levels.
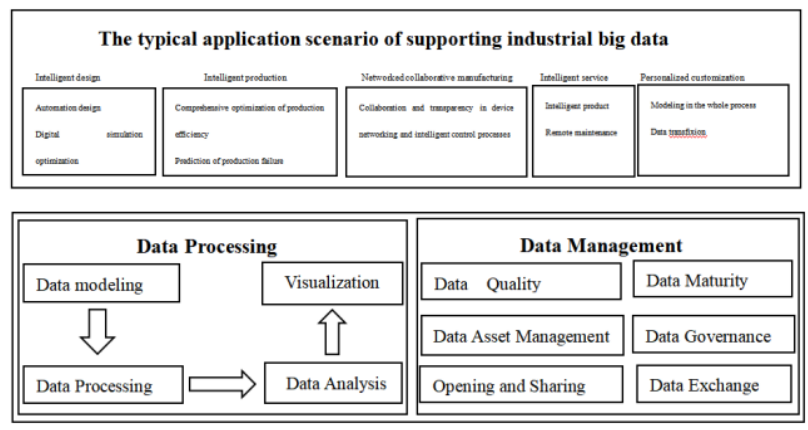

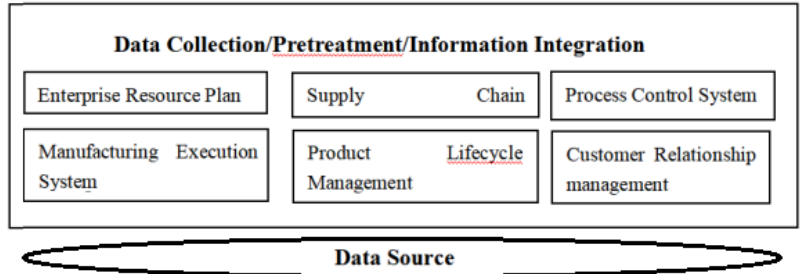

Figure 2. Three-tier architecture of intelligent manufacturing industry

Data sensing layer mainly realizes the collection and integration of data in all parts of the industry and gets through the data connection of the existing information system. The data sources include three categories. The first one is business data related to the production and operation of enterprises, which mainly includes lots of product research and development data ,customer information data, production data, logistics supply data and environmental data accumulated from enterprise information system. The second category is device object data, which refers to the equipment operation parameters, operating condition parameters, operating environment parameters and other data which can be used to evaluate the operation status of the production and equipment under the internet operation mode of industrial production equipment. The third kind is external data, which refers to the data of external Internet source of relevant enterprises related to industrial production activities.

Data analysis layer is the core of industrial big data. Its key target is to realize the industrial production data for intelligent process, intelligent products, intelligent new mode of new forms, intelligent management and intelligent service in the field of data processing and data management. Through data modeling and data processing, we can realize the visualization of data result and 3D industrial scene. And we can realize data management in data quality, capability maturity, data asset management, data open sharing and trading, etc.

Data application layer mainly generates visual description, control, decision making and other applications based on the results of data processing and data management in order to realize intelligent design, intelligent production, networked collaborative manufacturing, intelligent service, personalized customization and other typical intelligent manufacturing modes.

\section{Application prospect of intelligent manufacturing big data platform}

The result of industrial big data mining and analysis can be used in research, development and design, complex production process, product demand forecast, industrial supply chain optimization and industrial green development.

\subsection{Applications in the design field}


Traditional research, development and design got finished products by experiencing trail-manufacture, revise and iteration repeatedly in the lifetime of products, while industrial big data provides new advantages to research, development and design. From the perspective of traditional process, at an early stage, it is necessary for designers to start from preliminary investigation and put customer demands into consideration, and then find out loopholes in the market and relevant linkages by divergent thinking. However, under the influence of industrial big data, designers can publish their own products online. Users do not only pay for their favorites through the platform but also can form personalized customize products adding their thoughts.

\subsection{Applications in the optimization of complex production process}

Facing complex production process in the modern industrial manufacturing production lines, the industrial Internet of things is equipped with plenty of sensor devices. Real-time collected data can complete analysis in various forms including device diagnostics, electrical power consumption, energy analysis, quality accident analysis (violation of production regulations and failure parts), etc. Firstly, as for production process improvement, using big data in the production process can help to analyze the whole production flow chart and get to know how each link works. Once some process deviates from the standard one, there will be an alarm signal, so errors or bottlenecks will be more quickly detected and problems will be easier solved. In addition, big data technology can be used to build virtual model, simulate and optimize production process. When all processes and performance data can be rebuilt in the system, this kind of transparency will help manufacturers improve their production process. Secondly, in terms of energy consumption, by using sensors to supervise whole procedures during the process of equipment production, abnormal energy consumption or peak can be found timely to optimize the manufacturing process and reduce energy consumption.

\subsection{Applications in product demand forecast}

For product development, by analyzing current changes in demand and combining forms, the adjustments in the function and performance of the products can be made through focuses of consumers. First, web crawler technology and web-service technology are utilized to obtain related basic data, enterprise international data, user's behavior data and third-party data. And with persona, target user attributes can be described objectively and accurately and statistics in preferences and function demands can be made, which contributes to more acceptable products with core needs and providing more potential sales opportunities. And the persona is smart with system grouping to gain various target-user groups and then push targeted marketing. In addition, through historical data of multidimensional combination, the occupation and changes in regional demand, market popularity and ordinary combination and the lever of consumers can be observed to adjust product and distribution strategies.

\subsection{Applications in the optimization of industrial supply chain}

The application of industrial big data in supply chain is mainly embodied in the chain optimization. In other words, through information integration in the whole industry chain, the collaborative optimization and dynamic equilibrium in the production system are achieved, which further enhances productivity and reduces costs. The primary application includes optimization of supply chain distribution system and quick response to user requirements. Optimization of supply chain distribution system can help industrial enterprises obtain big data of supply chain by RFID electronic identity technology, networking technology and mobile Internet technology. Utilizing data in sales, production sensor and database from suppliers, industrial manufacturing enterprises can analyze and predict the needs in various regions of the world accurately to encourage efficiency of distribution and storage. Utilizing data produced by sensors in the product to analyze failure parts and confirm requirements, those enterprises can predict when and where integrating parts will in need; this largely improves timeliness of production, reduces repertory and optimizes the supply chain.

\subsection{Applications in industrial green development}

The target of green manufacturing is to realize least consumption, minimized or even no environmental pollution in the process of design, manufacturing, use and disposition. It emphasizes that information related to resource consumption and environmental information should be handled and considered integrally. Information flow, material flow and energy flow used to manufacture system should also be combined to integrate and optimize systematically. By monitoring and management in the process of recipe, crafts, purchases of materials, manufacturing, storage, transportation, usage, overhaul and scrap, taking data acquisition as the front and data analysis and mining as service, NGIT provides strong guarantee for manufacturing enterprise. The 2015 Industrial Green Development Special Action Implementation Plan officially released by Ministry of Industry and Information put "Organization and Implementation of Digital Energy Efficiency Promotion Plan" as an important task, which includes pilot project of green data center of key industries and the construction of national energy conservation monitoring and analysis platform. The new technology such as Internet, cloud computing, big data and industrial robots will guide and promote industrial equipment towards green development. It will certainly have a positive impact on industrial transformation, upgrading and green development through developing and perfecting manufacturing improvement program in equipment industry based on big data. 


\section{Big Data Service Circle of Intelligent Manufacturing Industry Cluster}

Intelligent manufacturing enterprises, in the help of electronic identification technology like RFID, Internet of Things technology and mobile Internet technology, obtain a complete big data of supply chain. The analysis on these data helps to achieve warehousing, distribution, sales efficiency and substantial cost reduction, thus optimize the supply chain. It integrates resources such as data of production, finance, management, purchasing, sales and consumer behaviour of intelligent manufacturing enterprises to help them find the best investment proportion of production factors through data analysis, realize the seamless convergence and business collaboration in the research and development of supply and marketing, management, production control and all business and financial procedures, as well as promote the integration, restructuring and optimization of the process of business, decision-making and management. The big data and cloud computing technology can further tap production relevance in intelligent manufacturing enterprises cluster to provide customized, temple, realtime business information analysis services, and to enhance strategic planning, access to competitive intelligence and industrial information sharing capabilities. After using ETL tools for big data analysis, classification and research, generating visual reports big data visualization technology, and sending customers information through the client software, it can provide intelligent manufacturing enterprises with timely, effective, accurate and comprehensive information service. Enterprises can monitor the running status of the product in real time by sensors embedded in the product and obtain the sales and customer data by the business platform. Through the analysis and prediction of these data, enterprises can carry out online value-added services such as fault warning, remote monitoring, quality diagnosis and remote operation and maintenance. With these online, customized and convenient valueadded services, the product value space is expanded, making the business model with the product as a core turn to the "manufacturing + service" model, and finally building the big data service system of the intelligent manufacturing industry cluster.

\section{Acknowledgements}

The study is supported by Natural Science Foundation of Fujian Provincial Science and Technology Department (No.2017J01508) and Key Projects of Fujian Provincial Education Department (No.JA15388) and Quanzhou Science and Technology Project (No.2014Z133) (NO.2012Z122).

\section{References}

1. White paper on industrial big data(2017 Edition). https://wenku.baidu.com/view/66f5 1af69fc3d5bbfd0 a79563c1 ec5da51e2d670.html(2017)

2. Jay Lee. From Bigdata to Intelligent Manufacturing.(2017)

3. Daxin Zhu, Xiaodong Wang.An Efficient Dynamic Programming Algorithm for a New Generalized LCS Problem.IAENG:International Journal of Computer Science, (2016)

4. Daxin Zhu, Xiaodong Wang.A Simple Polynomial Time Algorithm for the Generalized LCS Problem with Multiple Substring Exclusive Constraints.IAENG:International Journal of Computer Science , (2015) 